\title{
A Giant Pleomorphic Adenoma of the Palatine Arch in a 75-Year-Old Man: A Case Report with Review of Literature
}

\author{
${ }^{1}$ Santosh Kumar Swain, ${ }^{2}$ Mahesh Chandra Sahu, ${ }^{3}$ Rajashree Tripathy
}

\begin{abstract}
Pleomorphic adenoma (PA) is the most common benign tumor of the salivary glands and has both epithelial and mesenchymal tissues. It most commonly arises from the parotid or submandibular glands. Rarely, it arises from the minor salivary glands. We report here a case of pleomorphic adenoma arising from the soft palate and both sides of anterior tonsillar pillars in a 75 -year-old man. This patient was presenting painless slow growing large swelling in the soft palate over 20 years causing mechanical obstruction of airway and food. The entire tumor mass was excised along with overlying mucosa.
\end{abstract}

Keywords: Pleomorphic adenoma, Soft palate, Anterior pillar, Minor salivary glands.

How to cite this article: Swain SK, Sahu MC, Tripathy R. A Giant Pleomorphic Adenoma of the Palatine Arch in a 75-YearOld Man: A Case Report with Review of Literature. Int J Head Neck Surg 2015;6(1):23-25.

Source of support: Nil

Conflict of interest: None

\section{INTRODUCTION}

Pleomorphic adenoma (PA) is the commonest benign salivary gland tumor. It mainly occurs in the parotid gland and submandibular gland. If the tumor occurs in the minor salivary glands, the most common site is the palate, but this tumor can also occur in other sites include the upper lip, cheek, floor of the mouth, larynx and trachea. ${ }^{1}$ However, majority of minor salivary gland tumors are of the malignant variety. PA contains both epithelial and mesenchymal origin. ${ }^{2}$ Generally, it is mobile, except when it occurs in the hard palate. Intraoral mixed tumors, especially those

\footnotetext{
${ }^{1}$ Associate Professor, ${ }^{2}$ Research Associate, ${ }^{3}$ Professor

${ }^{1}$ Department of ENT, Institute of Medical Sciences and Sum Hospital, Siksha 'O' Anusandhan University, Bhubaneswar Odisha, India

${ }^{2}$ Central Research Laboratory, Institute of Medical Sciences and Sum Hospital, Siksha 'O' Anusandhan University Bhubaneswar, Odisha, India

${ }^{3}$ Department of Pathology, Institute of Medical Sciences and Sum Hospital, Siksha 'O' Anusandhan University, Bhubaneswar Odisha, India

Corresponding Author: Santosh Kumar Swain, Associate Professor, Department of ENT, Institute of Medical Sciences and Sum Hospital, Kalinga Nagar, Bhubaneswar, Odisha, India Phone: 9556524887, e-mail: swainsantoshbbsr@yahoo.com
}

noted within the palate, lack a well-defined capsule. Lesions of the palate frequently involve periosteum or bone. Approximately, $25 \%$ of benign mixed tumors undergo malignant transformation. ${ }^{3}$ Treatment for the pleomorphic adenoma is radical surgery. Inadequate resection leads to local recurrence. ${ }^{4}$ A case of a large PA of the minor salivary glands arising in the soft palate and both sides anterior pillars of the tonsils is described. It can be misdiagnosed as malignant tumor on blind clinical diagnosis in this advanced aged patient. This case report emphasizes on the need for awareness of its diverse presentation by the examining clinician that could influence the outcome greatly and for histopathological diagnosis of such growth before any definitive treatment.

\section{CASE REPORT}

A 75-year-old male presented with a painless slow growing large swelling (Fig. 1) over the soft palate for 20 years duration. The mass was causing mechanical obstruction of airway, food passage and causing speech problem. There was no preceding history of trauma and history was unremarkable. The patient's general condition was healthy. On examination, there was a $10 \times 7.5 \mathrm{~cm}$ sized, firm, nontender, circumsized lesion, faintly lobulated with smooth surface over the soft palate, uvula and bilateral anterior pillars of the tonsil. There was no regional lymphadenopathy, and his general and systemic examinations were normal. Computed tomography (CT) scan of palate did not show bony lesion (Figs 2 and 3). A punch biopsy was taken which confirmed the pleomorphic adenoma (Fig. 4). The entire tumor was excised in toto with overlying mucosa under general anesthesia with nasoendotracheal intubation. There has been no recurrence at 6 months of follow-up.

\section{DISCUSSION}

Pleomorphic adenoma also known as benign mixed tumor is the most common tumor of salivary glands. It rarely involves minor salivary glands. ${ }^{5}$ The term pleomorphic describes the embryogenic basis of origin of these tumors, which contains both epithelial and mesenchymal tissues. $^{6}$

Pleomorphic adenoma of minor salivary gland is most commonly seen in palate $(10 \%)$, followed by lip $(4 \%){ }^{7}$ 


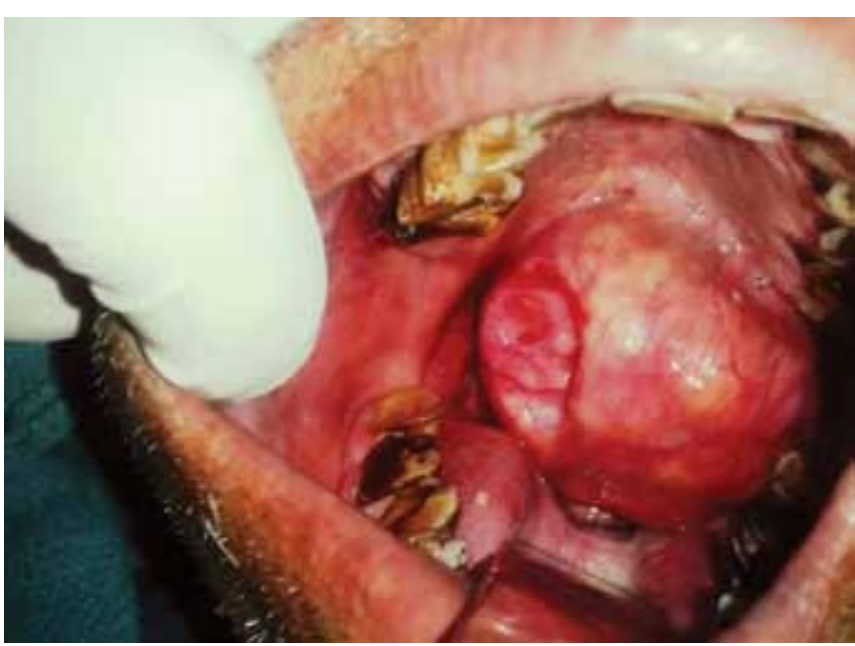

Fig. 1: Mass arising from palatine arch

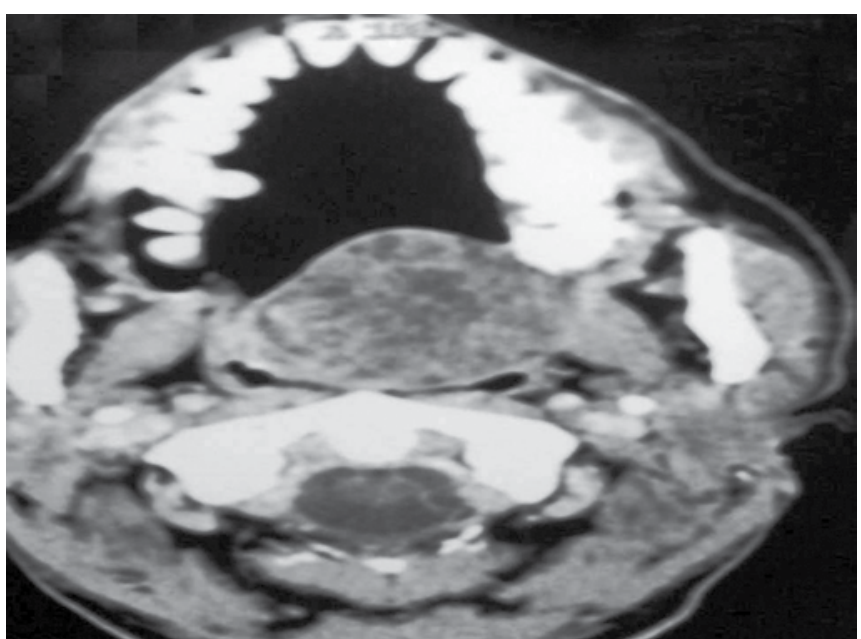

Fig. 3: CT scan of neck with coronal section showing mass

The uncommon sites are paranasal sinuses, larynx and trachea. PAs have also been reported in tongue, ${ }^{8}$ soft palate, ${ }^{9}$ uvula ${ }^{10}$ and even external auditory canal. ${ }^{11}$ Though, this tumor is not a rare one, these kinds of presentations are most often rare and are often misdiagnosed as malignant. Clinically, the patient presented a solitary, painless, slow growing, well-circumscribed palatal lump which is typical presentation of such tumor. The mechanical symptoms most commonly manifested by tumors of this location are dyspnea, dysphagia, acute airway obstruction and obstructive sleep apnea. ${ }^{12}$ In our case, the presenting complaints were dysphagia and difficulty in speech. Tumors arising in the minor salivary glands account for up to $22 \%$ of all salivary gland neoplasm. ${ }^{13,14}$ Majority are malignant without only $18 \%$ being benign. The commonest site of occurrence of PA of minor salivary glands is the palate followed by lip, buccal mucosa, floor of the mouth, tongue, tonsil, pharynx, retromolar area and nasal cavity. ${ }^{13,15}$

The important diagnostic tools are FNA biopsy and imaging. Cytological finding in PA are typically of mixed epithelial cells and mesenchymal elements. These features

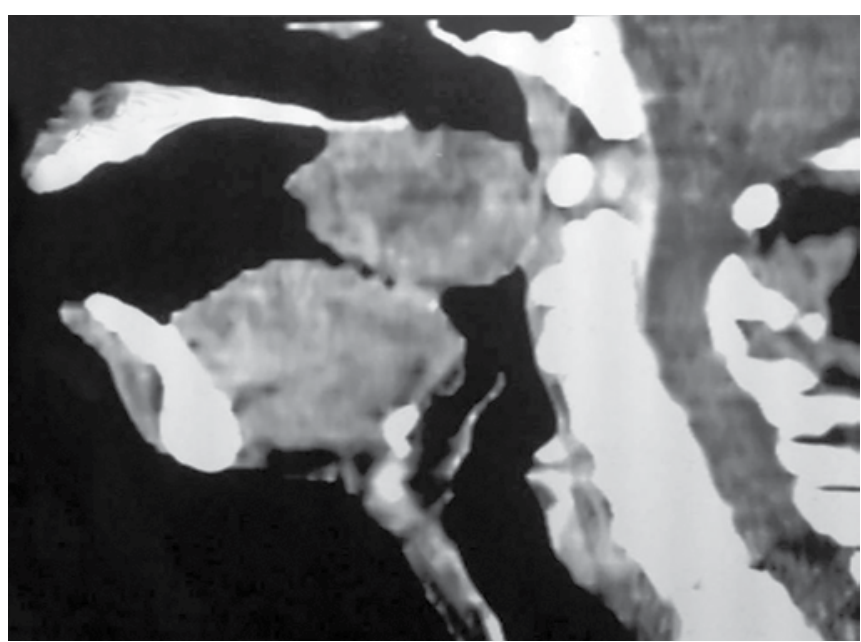

Fig. 2: Computed tomography scan of neck with sagittal view showing mass

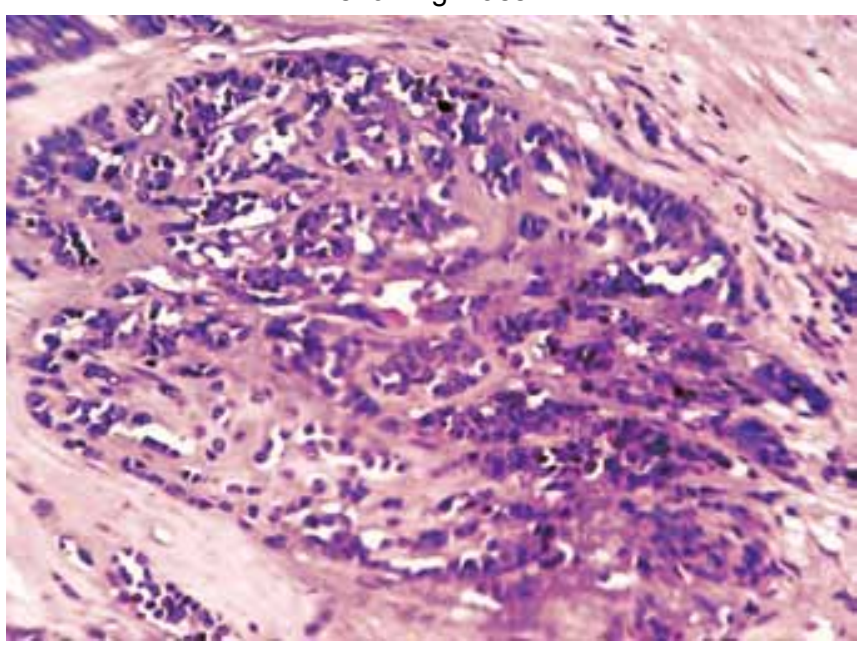

Fig. 4: HPE showing PA of minor salivary gland

were clearly illustrated in our case. The histopathological confirmation is mandatory in operating these tumors. However, differentiation from adenoid cystic carcinoma and polymorphous low grade adenocarcinoma may be difficult with FNA alone. ${ }^{16}$ Imaging with ultrasound, MRI, or CT may be used depending on the site and size of tumor. ${ }^{17}$ In our case, CT with contrast was primarily used to determine size and more importantly infiltration of lesion into the surrounding tissue. We found the lesion to be a $10 \times 7.5 \mathrm{~cm}$ soft-tissue dense mass, not involving adjacent tissues. CT scan with contrast enhancement is an important diagnostic tool. Presence of intact fat plane helps in distinguishing benign tumors from malignant.

Histopathologically, PA is an epithelial tumor of complex morphology, possessing epithelial and myoepithelial elements arranged in a variety of patterns and embedded in a mucopolysaccharide stroma. Formation of capsule is as a result of fibrosis of surrounding salivary parenchyma, which is compressed by tumor and is referred to as false capsule. ${ }^{18}$

The treatment of PA is essentially surgery. Though these benign tumors are apparently well encapsulated, 
resection of the tumor with an adequate margin of grossly normal surrounding tissue is necessary to prevent local recurrence as these tumors are known to have microscopic pseudopods like extension into the surrounding tissue due to 'dehiscences' in the false capsule. ${ }^{18}$ Spiro reported a recurrence in $7 \%$ of 1,342 patients with benign parotid neoplasms and $6 \%$ of patients with benign minor salivary gland tumors. ${ }^{1}$ It has been reported that rupture of the capsule on a benign PA frequently occurs during encluation or incomplete excision. Along the ruptured site, the myxoid material in the tumor spreads to the surrounding damaged soft tissue and distant sites through a venous or lymphatic route. ${ }^{19,20}$ Postoperative radiotherapy could possibly reduce the recurrence rate in such tumors. ${ }^{21}$ Adequate clearance of the tumor with a cuff of surrounding dispensable normal tissue is the key to successful treatment of such tumors. These tumors usually do not recur after adequate surgical excision. Most recurrence can be attributable to inadequate surgical techniques, such as simple enucleation leaving behind microscopic pseudopods like extensions. ${ }^{22}$

\section{CONCLUSION}

The majority of minor salivary gland tumors are malignant. Among benign tumors of the minor salivary glands, PA is the commonest, found most often in the oral cavity. The palatine arch is a very rare site for this tumor. This is also very rare occurrence in advanced age. Complete surgical excision is the treatment of choice.

Pleomorphic adenoma, though a common entity, is still a challenging tumor for pathologist, radiologist and the surgeon. Its diverse histological and topographical property makes the tumor special. The examining clinician and treating surgeon must be aware of its recurrence, longevity, and malignant potential if incorrectly diagnosed or treated.

\section{ACKNOWLEDGMENT}

The authors are thankful to Chairman and managing member of Siksha O Anusandhan University, Bhubaneswar, for their encouragement.

\section{REFERENCES}

1. Lomeo P, Finneman J. PA of the soft palate. Otolaryngol Head Neck Surg 2001;125(1):122.

2. Suen JY, Synderman NL. Benign neoplasms of the salivary glands. Otolaryngology, Head and Neck Surgery 1993;2(1):1029-1042.
3. Debnath SC, Saikia AK, Debnath A. PA of the palate. J Maxillofac Oral Surg 2010;9(4):420-423.

4. Clauser L, Mandroli S, Dallera V, Sarti E, Galie M, Cavazzini L. PA of the palate. J Craniofac Surg 2004;15(6):1026-1029.

5. Paul L, Silvera VM, Atayde AP, Michael JC, Atayde RR. Disorders and tumors of the salivary glands in children. Otolaryngologic Clinics of North America 2015;48(1):153-173.

6. Batsakis JG. Neoplasms of the minor and lesser major salivary glands. In: Tumors of the Head and Neck. The Williams and Wilkins Company, Baltimore; 1981. p. 38-47.

7. Ellis GL, Auclair PL. Tumours of the salivary glands, atlas of tumour pathology. 3rd series, Facsicle 17. Washington: Armed Forces Institute of Pathology; 1996.

8. Ghosh SK, Saha J, Chandra S, Datta S. PA of the base of the tongue: a case report. Ind J Otolaryngol Head Neck Surg 2011; 63(2):113-114.

9. Daryani D, Gopakumar R, Ajila V. PA of soft palate: myoepithelial cell predominant. Indian J Dent Res 2011;22(6): 853-856.

10. Su A, Apple SK, Moatamed NA. PA of the uvula, clinical reminder of a rare occurrence. Rare Tumours 2012;4(1):16.

11. Koyuncu M, Karagoz F, Kiliacarslan H. PA of the external auditory canal. Eur Arch Otorhinolaryngol 2005;262(12): 969-971.

12. Yoshihara T, Suzuki S. PA of tongue base causing dysphagia and dyspnoea. J Laryngol Otol 2000;114(10):793-795.

13. Spiro SH. Salivary neoplasm: overview of a 35 years experience with 2807 patients. Head Neck Surg 1986;8(3): 177-184.

14. Cohen MA. PA of the cheek. Int J Oral Maxillofac Surg 1986; 15(6):777-779.

15. Varghese BT, Sebastian P, Abraham EK, Mathews A. PA of minor salivary gland in the parapharyngeal space. World J Surg Oncol 2003;1(1):2.

16. Das D, Anim JT. PA of the salivary gland: to what extent does fine needle aspiration cytology reflect histopathological features? Cytopathology 2005;16(2):65-70.

17. Lingam RK, Daghir AA, Nigar E, Abbas SA, Kumar M. PA (benign mixed tumour) of the salivary glands: its diverse clinical, radiological, and histopathological presentation. $\mathrm{Br}$ J Oral Maxillofac Surg 2011;49(1):14-20.

18. Heeneman H. Parapharyngeal space tumours. In: Scott Brown's Otolaryngology. 5th ed. Edited by Kerr AG. Butterworth and Co Ltd 1987;2(1):380-391.

19. Marioni G, Marino F, Stramare R, Marchese-Ragona R, Stafferi A. Benign metastasizing PA of the parotid gland: a clinicopathologic puzzle. Head Neck 2003;25(12):1071-1076.

20. Sabesan T, Ramchandani PL, Hussein K. Metastasising PA of the parotid gland. Br J Oral Maxillofac Surg 2007;45(1): 65-67.

21. Perez CA, Brady LW. Treatment of pleomorphic adenoma. In Principles of practices of radiation oncology. JB Lippincott Company Philadelphia 1987;2(3):521.

22. Feinmesser R, Gay I. PA of the hard palate: an invasive tumour. J Laryngol Otol 1983;97(12):1169-1171. 